\title{
Costs and benefits of the symbiosis between the anemoneshrimp Periclimenes brevicarpalis and its host Entacmaea quadricolor
}

\author{
Daphne G. Fautin ${ }^{1, *}$, Chau-Chih Guo ${ }^{2}$, Jiang-Shiou Hwang ${ }^{2}$ \\ ${ }^{1}$ Department of Systematics and Ecology, University of Kansas, Lawrence, Kansas 66045, USA \\ ${ }^{2}$ Institute of Marine Biology, College of Fisheries Science, National Taiwan Ocean University, Keelung, Taiwan 20224, \\ Republic of China
}

\begin{abstract}
Shrimp of the species Periclimenes brevicarpalis (family Palaemonidae, subfamily Pontoniinae) are obligate associates of sea anemones. To assess the nutritional relationship between the shrimp and one of its hosts, Entacmaea quadricolor (family Actiniidae), we conducted 10 replicate $30 \mathrm{~d}$ experiments. An experiment comprised 6 treatments: a pair of fed shrimp, a pair of unfed shrimp, a fed pair of shrimp plus an anemone, an unfed pair of shrimp plus an anemone, a fed anemone, and an unfed anemone. Shrimp survival was 6 (of 20) for unfed shrimp lacking an anemone, 17 for fed shrimp lacking an anemone, and 19 for shrimp with a host, whether fed or not. Longevity of unfed anemoneshrimp kept alone (23 d) was significantly less than that of shrimp in the other treatments ( 28 or 29 d). Larvae were released by all female shrimp with an anemone but by only 7 of 10 unfed and 8 of 10 fed ones kept alone. Magnitude of growth, interval between molts, and number of larval releases were all dependent on whether a shrimp had been kept with an anemone but were independent of whether it had been fed. Shrimp clipped and ate anemone tentacles: unfed anemones with shrimp lost most or all of their tentacles, and many fed ones did so as well, but anemones kept without shrimp did not. Magnitude of tentacle loss was dependent on whether the anemone had been with shrimp but was independent of whether it had been fed. Thus, there is a benefit to the shrimp from this association and potentially a cost to the anemone, but anemones with shrimp in nature always appear to have normally long and numerous tentacles.
\end{abstract}

KEY WORDS: Actiniaria S Sea anemone $\cdot$ Caridea $\cdot$ Parasitism

\section{INTRODUCTION}

Many tropical caridean shrimps are symbiotic with invertebrates and some vertebrates; cnidarians host the greatest variety of them (Bruce 1976). (We use the term 'symbiotic' literally, in the sense of living together, without implication of cost or benefit.) It is widely assumed that living in - or even beside - a cnidarian confers protection on the cnidarian's associate (e.g. Bruce 1976 , Fautin \& Allen 1992). Few caridean/cnidarian symbioses have been analyzed in sufficient detail to determine whether the cnidarian host benefits or suffers.

\footnotetext{
·E-mail: fautin@kuhub.cc.ukans.edu
}

Smith (1977) demonstrated that the Caribbean snapping shrimp Alpheus armatus (family Alpheidae) benefits its host sea anemone Bartholomea annulata, protecting it from predation by the annelid Hermodice carunculata. Thus, the relationship between $A$. armatus and $B$. annulata is mutualistic. By contrast, the shrimp Periclimenes brevicarpalis (family Palaemonidae, subfamily Pontoniinae) tears tentacles from its anemone host and may eat them (Suzuki \& Hayashi 1977, Bruce \& Svoboda 1983). Suzuki \& Hayashi (1977) proposed that the symbiosis between this shrimp (as well as 2 other species) and its host anemones be classed as parasitic, based on both field and laboratory research, but found no 'heavy damage' (p. 203) to the host anemone from the shrimp. 
Periclimenes brevicarpalis is an obligate associate of at least 8 species of tropical sea anemones throughout its range from the central Pacific to the Red Sea (Bruce \& Svoboda 1983). After observing in the laboratory a specimen of $P$. brevicarpalis from Taiwan use its chelipeds to clip tentacles of its host actinian Entacmaea quadricolor, we attempted to determine whether tentacle-clipping contributes positively to the survival and/or growth of the shrimp, and whether there is a perceptible cost to the actinian.

Suzuki \& Hayashi (1977) identified the anemone hosts of Periclimenes brevicarpalis in Japan as Parasicyonis actinostroides [presumably a lapsus calami for $P$. actinostoloides (that is, an author's error, not a typographical error; see International Code of Zoological Nomenclature 1985)], Parasicyonis maxima, and Radianthus maculata. The correct identification of the first 2 of these symbionts is Entacmaed quadricolor (see Dunn 1981, Fautin \& Allen 1992); P. actinostoloides and $P$. maxima are deep-water actinians belonging to a different suprafamilial taxon than Entacmaea (Carlgren 1949). The genus Radianthus [the senior synonym of which is Heteractis (Dunn 1981) I contains no species $R$. maculata (see Carlgren 1949, Dunn 1981), and so the identity of that host species is unknown. Bruce \& Svoboda (1983) made their observations on shrimp living with the anemone Cryptodendrum adhaesivum, which, like E. quadricolor, may also host clownfish (Dunn 1981, Fautin \& Allen 1992)

\section{MATERIALS AND METHODS}

Experiments were conducted at National Taiwan Ocean University (NTOU), Keelung, using the shrimp Periclimenes brevicarpalis and its host sea anemone Entacmaea quadricolor. Experiments were begun 1 to $3 \mathrm{~d}$ after animals were collected; each was $30 \mathrm{~d}$ in duration. A total of 10 replicates was done, as many as 3 simultaneously (Table 1).

An experiment comprised 6 treatments: a pair of shrimp $(1$ male and 1 female that had been collected from a single anemone), fed (coded $S / F$ ); a pair of shrimp, unfed $(\mathrm{S} / \mathrm{U})$; a pair of shrimp plus an anemone, fed (S+A) F); a pair of shrimp plus an anemone, unfed $(S+A / U) ; a n$ anemone only, fed $(\mathrm{A} / \mathrm{F})$; and an anemone only, unfed $(\mathrm{A} / \mathrm{U})$. Mortality of both shrimp and anemones was lower than in a preliminary experiment with 4 anemones and/or 4 shrimp per tank; agonistic interaction between shrimp (observed also by Bruce \& Svoboda 1983) was much greater in the preliminary experiment.
Animals were maintained in glass aquaria $30 \times 20 \times$ $20 \mathrm{~cm}$ containing $12 \mathrm{l}$ of aerated seawater from NTOU's seawater system. Aquaria were kept in the university's aquarium room at ambient temperature, which varied from 23 to $28^{\circ} \mathrm{C}$, depending on outside air temperature, and under artificial lighting, which was on an approximately $12 \mathrm{~h}$ light: $12 \mathrm{~h}$ dark cycle. Fed animals were given brine shrimp (Artemia) nauplii to excess; feeding was mostly every day or on alternate days, but sometimes as many as $4 \mathrm{~d}$ elapsed between feedings and in 3 experiments there was one interval of 1 wk. Water was normally changed every 3 to $5 \mathrm{~d}$, but water that became smelly or cloudy was changed more frequently. Table 1 provides details of experiments.

Animals were observed daily; molting and release of larvae by shrimp, fission of anemones, and deaths of shrimp and anemones were recorded. Dead animals were removed from the tank. Measurements of shrimp (length from postorbital margin to telson) and anemones (pedal disc diameter) were made on Days 2 and 30 of each replicate experiment except the first. State of anemone tentacles was scored as ++ (tentacles as numerous and long as is typical of animals in the field), + (tentacles somewhat sparser and/or shorter than is typical of animals in the field), $+/-$ (tentacles sparse and most much shorter than is typical of animals in the field), and - (few tentacles present and/or most mere stubs\}. Animals were photographed weekly and on the second and last days of the experiment.

Results of experiments were analyzed by $\chi^{2}$. Student's $t$-test, the $G$-test for independence, and the a posteriori simultaneous test procedure (STP) statistic, a nonparametric test equivalent to 2-way ANOVA (Sokal \& Rohlf 1969).

Following the end of the last series of experiments, we put each surviving shrimp individually into a freshly collected specimen of Entacmaea quadricolor for $10 \mathrm{~min}$ to observe acclimation and tentacle-clipping behavior. 


\section{RESULTS}

Shrimp survival and size change, number and interval of molts, and number of replicates in which larvae were liberated in the 4 treatments that included shrimp are shown in Table 2 .

Number of shrimp surviving was lower in the S/U treatment than in the other 3 treatments $\left(\chi^{2}=7.6557\right.$; $\mathrm{p}<0.01)$. Correspondingly, their longevity was less: tested by the STP statistic, S/U $<\mathrm{S} / \mathrm{F}(\mathrm{U}=306.5$; $\mathrm{p}<$ $0.05)$ and $\mathrm{S} / \mathrm{U}<\mathrm{S}+\mathrm{A} / \mathrm{U}$ and $\mathrm{S}+\mathrm{A} / \mathrm{F}(\mathrm{U}=333.5$ and 332 , respectively; $p<0.01$ ). Eight of the shrimp deaths immediately followed molting. Of the 7 instances in the $\mathrm{S} / \mathrm{U}$ treatment, the molted individual was eaten by its mate $(4$ females and 3 males were eaten: all males were smaller than the females that ate them, 1 cannibalized female was smaller and 2 were larger than their mates, and the size of the other was not recorded); the dead individual was not eaten in the other post-molting death (treatment $\mathrm{S} / \mathrm{F}$ ). For the 2 instances of cannibalism not associated with molting one each in S/F and S/U - a larger female was eaten.

Females molted 97 times and males 96 times during the experiment. Number of molts was independent of whether the shrimp were fed $(G=10.9318)$ but was dependent on whether they were kept with an anemone $(G=12.2264$; $p<0.05)$.

Shrimp initially were 10.8 to $28.8 \mathrm{~mm}$ long. Females averaged $21.56 \mathrm{~mm}$ and males $18.73 \mathrm{~mm}$, a difference significant at $p<0.001$. Average length change of survivors at the end of the experiment is given in Table 2 . Because of small numbers, data for each treatment were grouped for analysis according to whether there had been positive, negative, or no change in length. Growth was independent of whether shrimp were fed $(G=5.7210)$ but was dependent on whether they were kept with an anemone $(G=22.8116$; $\mathrm{p} \ll 0.005\}$.
Table 2. Periclimenes brevicarpalis. Indicators of survival and well-being of anemoneshrimp in 10 replicate $30 \mathrm{~d}$ experiments, beginning with 2 shrimp per treatment. $S+A / F$ : shrimp plus anemone, fed; $\mathrm{S}+\mathrm{A} / \mathrm{U}$ : shrimp plus anemone, unfed; $\mathrm{S} / \mathrm{F}$ : shrimp, fed; S/U: shrimp, unfed

\begin{tabular}{|c|c|c|c|c|}
\hline & $\mathrm{S}+\mathrm{A} / \mathrm{F}$ & $S+A / U$ & $\mathrm{~S} / \mathrm{F}$ & $S / U$ \\
\hline $\begin{array}{l}\text { No. shrimp surviving } \\
\text { to end of expt }\end{array}$ & 19 & 19 & 17 & $6^{d}$ \\
\hline $\begin{array}{l}\text { Shrimp mean } \\
\text { longevity (d) }\end{array}$ & 29.70 & 29.80 & 28.20 & $22.70^{b}$ \\
\hline $\begin{array}{l}\text { Day on which first } \\
\text { shrimp died }\end{array}$ & 24 & 26 & 8 & 8 \\
\hline $\begin{array}{l}\text { Molts per shrimp } \\
\text { (total no.) }\end{array}$ & $3.08(61)$ & $2.52(50)$ & $2.56(49)$ & $2.16(33)$ \\
\hline $\begin{array}{l}\text { Mean interval } \\
\text { between molts (d) }\end{array}$ & 8.68 & 10.20 & 9.48 & 10.87 \\
\hline $\begin{array}{l}\text { Mean length } \\
\text { change }(\mathrm{mm})^{c}\end{array}$ & 2.49 & 1.42 & 0.34 & -0.28 \\
\hline $\begin{array}{l}\text { No. replicates } \\
\text { larvae released }\end{array}$ & 10 & 10 & 8 & 7 \\
\hline $\begin{array}{l}\text { Mean first day } \\
\text { of larval release }\end{array}$ & 8.1 & 9.0 & 7.9 & 6.6 \\
\hline \multicolumn{5}{|c|}{$\begin{array}{l}\text { d Less than in the other } 3 \text { treatments }(\mathrm{p}<0.01) \\
{ }^{\mathrm{b}} \mathrm{S} / \mathrm{U}<\mathrm{S} / \mathrm{F} \text { at } \mathrm{p}<0.05 ; \mathrm{S} / \mathrm{U}<\mathrm{S}+\mathrm{A} / \mathrm{U} \text { and } \mathrm{S}+\mathrm{A} / \mathrm{F} \text { at } \mathrm{p}<0.01 \\
\text { 'Independent of whether shrimp had been fed but depen- } \\
\text { dent on whether shrimp had been kept with an anemone } \\
(\mathrm{p} \& 0.005)\end{array}$} \\
\hline
\end{tabular}

All female shrimp kept with an anemone released larvae, most multiple times, whereas not all of those kept alone did so and only 2 (both in the S/F treatment) did so more than once (Fig. 1). Modal interval between larval releases was $18 \mathrm{~d}$ for $\mathrm{S}+\mathrm{A} / \mathrm{F}$ and $9 \mathrm{~d}$ for $\mathrm{S}+\mathrm{A} / \mathrm{U}$. Data for each treatment were analyzed according to whether larvae had been released once, more than once, or not at all. Number of releases was independent of whether the shrimp had been fed $(G=0.2415)$
Fig. 1. Periclimenes brevicarpalis. Number of larval releases by shrimp during 10 replicate 30 d experiments. Number was independent of whether the shrimp had been fed but was dependent on whether the shrimp had been kept with an anemone. S: shrimp; A: anemone; F: fed; U: unfed

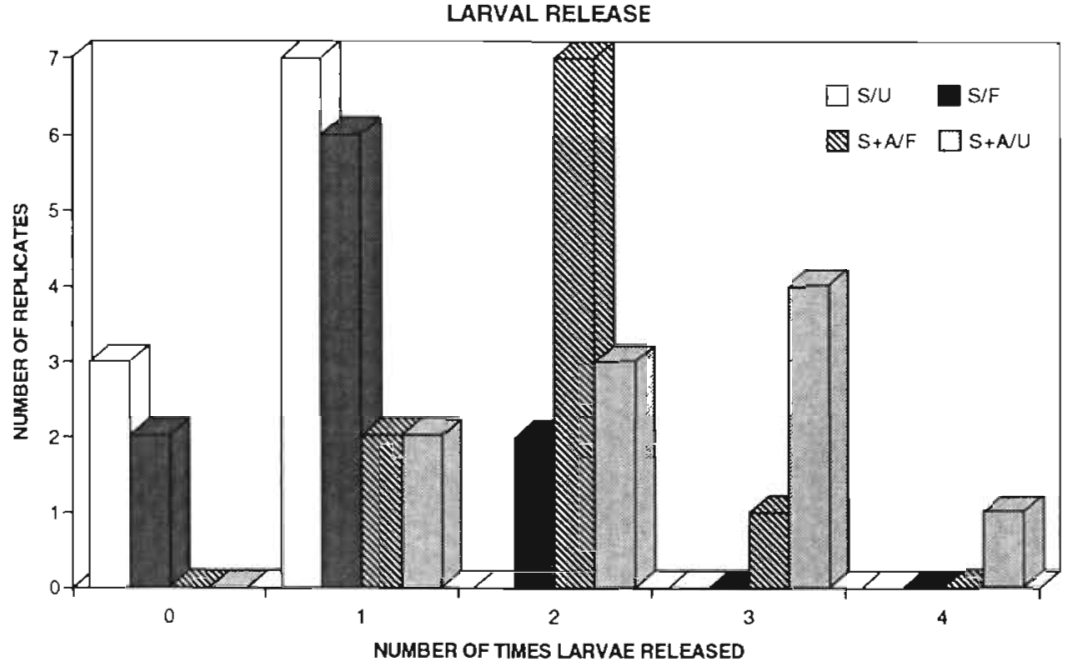


CONDITION OF ANEMONE TENTACLES AT EXPERIMENT'S END

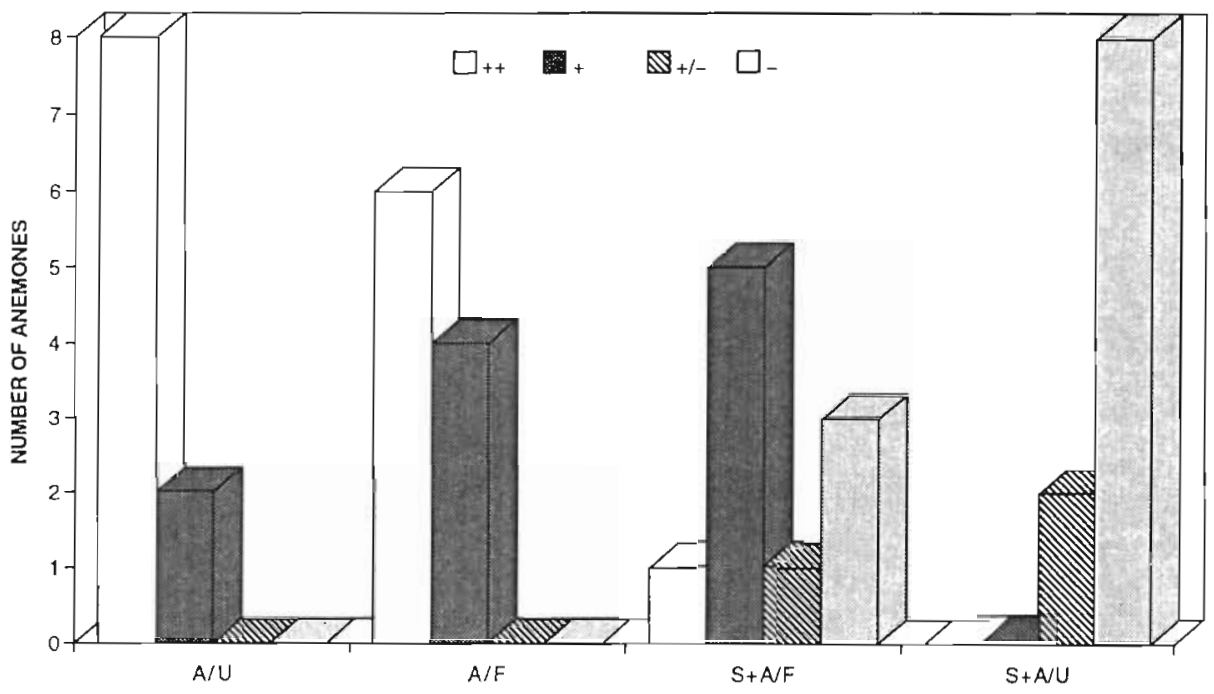

Fig. 2. Entacmaea quadricolor. Condition of sea anemone tentacles at end of 10 replicate $30 \mathrm{~d}$ experiments. -: Only tentacle stubs; +/-: mostly stubs with a few long tentacles; + : sparse long tentacles; +t: original condition of dense long tentacles. See Figs. 3-8 for photographs of anemones in each condition. Tentacle condition was independent of whether the anemones had been fed but was dependent on whether they had been kept with a shrimp but was dependent on whether the shrimp had been kept with an anemone ( $G=24.3418 ; p \ll 0.005)$. Of shrimp not with an anemone, first larval release occurred between Days 3 and 15 of the experiment (mean 7.3); of those with an anemone, first release was between Days 2 and 28 (mean 8.7). Average day of first larval release was 8.0 ; first release day did not differ significantly among the 4 treatments $\left(\chi^{2}=0.3833\right)$. No female released larvae after her mate had died.

All sea anemones survived all replicate experiments. However, most of those with shrimp lost some or all of their tentacles (Figs. 2,6-8). Tentacle condition (Fig. 2) was independent of whether the anemones had been fed $(G=7.5830)$, but was dependent on whether they had been kept with a shrimp $(G=32.9458$; $\mathrm{p} \ll 0.005)$. All anemones we have seen in the field - throughout their extensive range, even where anemoneshrimps are abundant - had tentacles we would score as ++ (Figs. $3 \& 4$ ).

Fission occurred in 4 anemones, 3 during 1 replicate (Table 1): 2 were in treatment $S+A / F$, and 1 each were in treatments $A / F$ and $A / U$ Pedal disc diameter of anemones was about 30 to $50 \mathrm{~mm}$, but was sufficiently changeable that we could reliably ascertain no difference in it between the beginning and end of a replicate. All anemones had paled by the end of $30 \mathrm{~d}$. The only phenomenon that may be related to experimental conditions or time of year was fission of anemones, all 4 instances of which occurred in September or October, 3 in 1 replicate. However, anemones in the 2 replicates in which fission occurred were from different sites (Table 1)

Shrimp do not necessarily ingest all the tentacles they clip: they were observed 'tasting' and then discarding tentacles, and tentacles were sometimes scattered on the aquarium floor around the anemone, whether the animals had been fed or not.

The surviving 6 shrimp from one of the final replicates (the females in both unfed tanks had died) were introduced individually into a freshly collected anemone. Neither the 3 shrimp that had been isolated from an anemone nor the 3 that had been living with one showed acclimation behavior, nor did any clip a tentacle during the 10 min observation.

\section{DISCUSSION}

In nature, shrimp of the species Periclimenes brevicarpalis are presumably protected against predators by living with sea anemones. We conclude from our experiments that even in the absence of predators, their growth, longevity, and fecundity are enhanced by living with a sea anemone, a finding consistent with the obligate nature of this shrimp's symbiosis. Magnitude of growth (both length change and molting) and reproduction were dependent on an anemone but not on the food we provided, although the Artemia nauplii sufficed to allow at least some shrimp kept alone to survive $30 \mathrm{~d}$.

Svoboda found that ovaries do not develop without a host (Bruce \& Svoboda 1983), but based on the 2 shrimp in the S/F treatment that produced eggs during the experiment (Fig. 1), we conclude that once differentiated, ovaries can function in the absence of a host. Whether they were ovigerous was not recorded when the shrimp were collected, but we infer (from interval between shrimp capture and first larval release) that first larval releases by shrimp not with anemones, and all but one each in the $S+A / U$ and 
$\mathrm{S}+\mathrm{A} / \mathrm{F}$ treatments, were from eggs produced before the shrimp were collected. If our inference is correct, the prevalence of ovigerous Periclimenes brevicarpalis in Taiwanese waters during the months of the experiment was 70 to $90 \%$

An interval of about $9 \mathrm{~d}$ between larval releases is biologically reasonable, being similar to the average interval between molts. Paradoxically, a higher proportion of unfed shrimp kept with an anemone produced eggs every molt than did fed ones. Molting is not entirely equivalent to growth, as evidenced by length change data, for shrimp in the $\mathrm{S}+\mathrm{A} / \mathrm{U}$ treatment grew much more than those in the S/F treatment.

The advantage to shrimp living with sea anemones is presumably at least in part from eating anemone tentacles. Tentacles of captive anemones may diminish in size (Fautin \& Allen 1992) as the normal sloughing of tissue continues from the distal end, but new tissue is not generated proximally, probably because of poor nutrition. This was not the cause of tentacle loss in this experiment - unfed anemones lacking shrimp had long, typically bulbed tentacles (Figs. 2 \& 4), whereas most or all tentacles of most sea anemones kept with shrimp were removed by the shrimp. This did not diminish anemone survivorship during the experiment. Paling of anemones was presumably due to loss of their zooxanthellae (endosymbiotic dinoflagellates) (Dunn 1981) because of the level and quality of light in the aquarium room.

Whether Periclimenes brevicarpalis should be considered parasitic on Entacmaea quadricolor, as proposed by Suzuki \& Hayashi (1977), depends on how parasitism is defined. In addition to density of parasites affecting pathogenicity - if any - of a parasite (e.g. Cheng 1991), factors such as age or health of host affect intensity of a parasite's effect (Kuris 1974). Our experiment potentially increased the intensity of a shrimp's impact on an anemone in 3 ways.

(1) A shrimp deprived of alternative sources of food was forced to subsist on its anemone. We infer that the unfed shrimp were hungry: cannibalism was in postmolt, unfed shrimp, whereas the single post-molt, fed shrimp that died was not cannibalized. That the shrimp are not voracious predators on anemone tentacles was illustrated by the shrimp kept without an anemone and not fed for $30 \mathrm{~d}$ that did not immediately clip an anemone's tentacles when they had an opportunity to do so.

(2) Some host anemones were deprived of food as well, possibly compromising their health. Moreover, lacking sunlight, all were deprived of the fixed carbon that we presume, by analogy with other sea anemones (data summarized by Steen 1988), is normally provided to the animals from their zooxanthellae. Anabolic activities of anemones in nature may be better able to compensate for the activities of the shrimp than in the artificially lighted laboratory, particularly when food was withheld.

(3) In nature, shrimp may not be confined to a single host individual [although most individuals of its congener Periclimenes ornatus are (Omori et al. 1994)l. The host Entacmaea quadricolor commonly exists in large clones (Dunn 1981), which would facilitate shrimp movement between individuals. In a semi-quantitative field survey (Guo et al. in press), 42 of 100 specimens of E. quadricolor harbored a total of 55 shrimp (1.3 shrimp per anemone), 14 of which were Periclimenes brevicarpalis ( 0.3 shrimp per anemone). Thus, the density of shrimp (and especially of $P$. brevicarpalis) is lower in the field than in our experiment. The inference of lower natural densities is also supported by our observation of agonistic interaction among shrimp in the preliminary experiment with 4 shrimp and 4 anemones.

The potential we demonstrated of at least some individuals of Periclimenes brevicarpalis to live for extended periods on only anemone tentacles could become important under conditions of low food availability or high shrimp:host densities (due to shrimp population increase and/or anemone mortality). We have no evidence that the act of tentacle-clipping harms the host. Whether extreme loss of tentacles, as illustrated in Fig. 8, is harmful to the anemone could not be confirmed in our short-term experiment, for we found no effect on survival, the only parameter of wellbeing we could measure in the anemones. This is not surprising, given the long lifespans and slow metabolism of sea anemones. We infer from the appearance of anemones in the field and the undiminished density and length of tentacles in most anemones in the S+A/F treatment that an anemone can replace tentacles as rapidly as they are removed by a shrimp, so such damage occurs only under exceptional circumstances. Indeed, we assume an association that commonly resulted in an anemone with extremely clipped tentacles would be unstable: the anemone would have difficulty capturing food, and a shrimp that reduced the number and size of its host's tentacles might thereby deprive itself of the beneficial aspects of life with an anemone, i.e. refuge among the tentacles and the food supplement/reserve they represent.

During periods of low food availability, if the anemone sustains it, the shrimp may, indeed, be parasitic. But the effect of a symbiont on its host can vary through time (e.g. Toft 1991), and a relationship that is parasitic under some circumstances need not always be (Thompson 1994), so the net lifetime effect, rather than any short-term effect, may govern the interrelations of organisms. Although the shrimp seems to have the potential to harm its host, it apparently normally does not do so. 


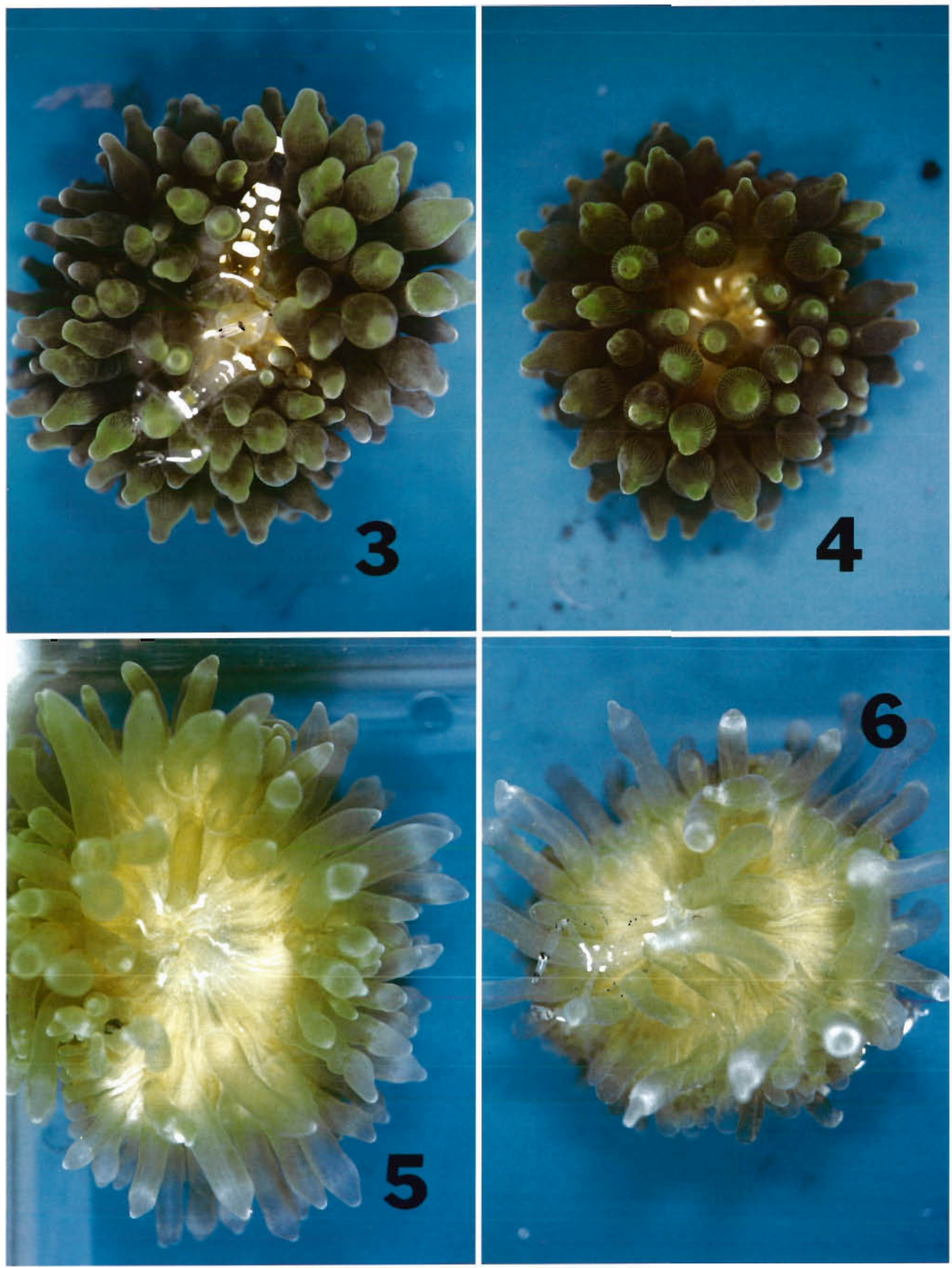



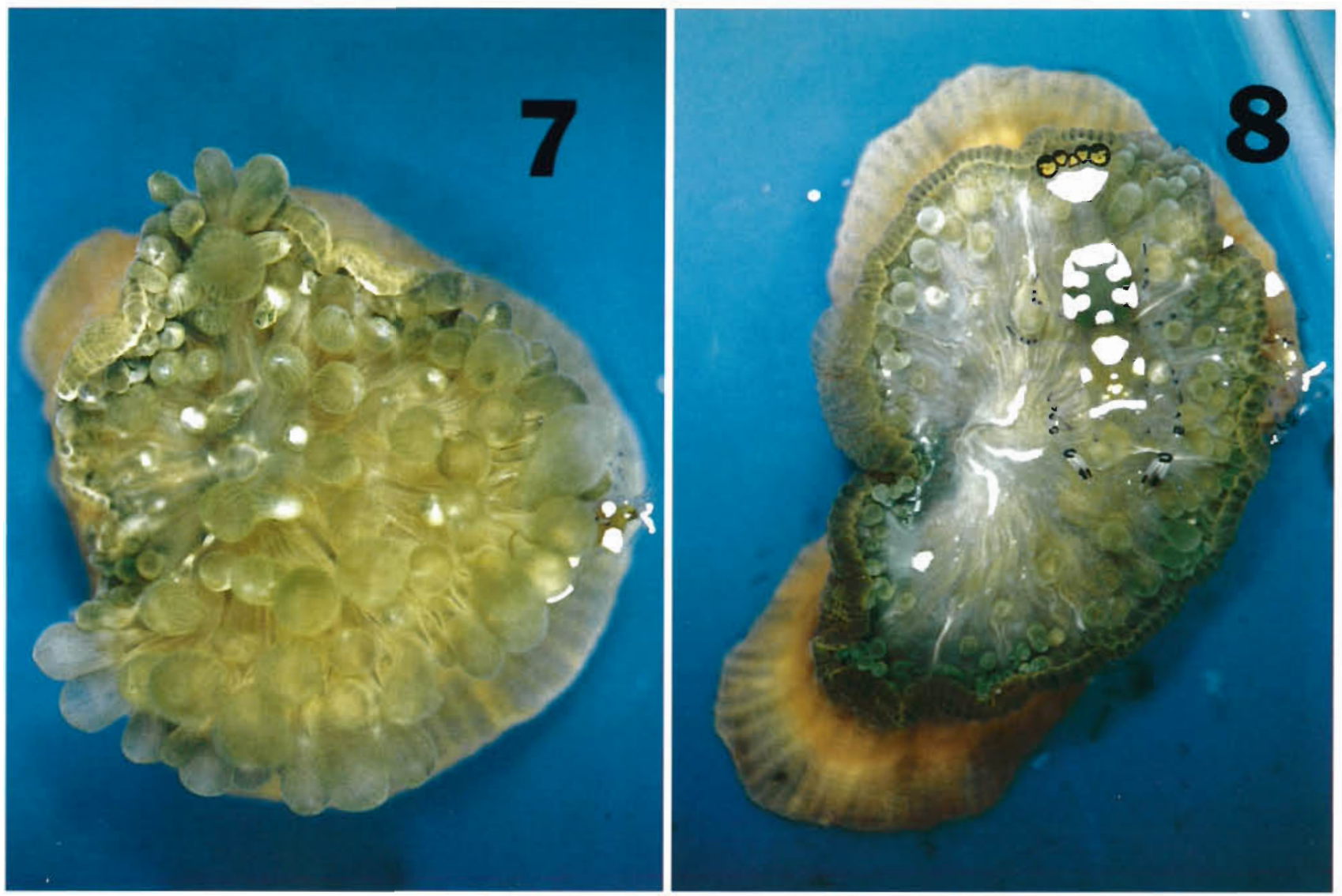

Figs. 3-8. Entacmaea quadricolor. Photographs of sea anemones at the end of representative replicates of each of 4 treatments plus a typical anemone at the beginning of the experiment. Fig. 3. Initial condition (Day 2), with 2 individuals of Periclimenes brevicarpalis (treatment $\mathrm{S}+\mathrm{A} / \mathrm{U}$, replicate 10). Fig. 4. Anemone on Day 30, treatment $\mathrm{A} / \mathrm{U}$ (replicate 9), condition ++ . Fig. 5. Anemone on Day 30, treatment A/F (replicate $\overline{5}$ ), condition +. Figs. 6 \& 7. Anemones and shrimp on Day 30, treatment $\mathrm{S}+\mathrm{A} / \mathrm{F}$ anemone in Fig. 6, condition + (replicate 5); anemone in Fig. 7, condition $+/$ - (replicate 3). Fig. 8. Anemone and shrimp on Day 30 treatment $\mathrm{S}+\mathrm{A} / \mathrm{U}$ (replicate 6$)$, condition -

To understand both sides of the interrelationship, research is needed on the effects of the symbiosis on the host anemone. Although our findings are consistent with the anemone being a facultative symbiont, caution must be used in extrapolating conclusions reached about the nature and evolution of the symbiosis from field studies in Taiwan or Japan. In the equatorial tropics, individuals of Entacmaea quadricolor are dependent on symbiotic fish to survive, whereas in subtropical areas such as Taiwan and Japan, where predators of the host anemones are few or absent, they survive without anemonefish (Godwin \& Fautin 1992). Presumably, as for the anemonefish symbiosis, the anemoneshrimp symbiosis is primarily an adaptation to conditions of the equatorial tropics, so the situation outside the tropics may be atypical.

Finally, as in the case of anemonefish (Fautin 1991), the anemoneshrimp symbiosis is not a unitary phenomenon. In this and several other trials involv- ing shorter periods of separation of shrimp and hosts, we saw no acclimation behavior, as has been reported for Periclimenes anthophilus (see Levine \& Blanchard 1980, Crawford 1992) and P. rathbunae (see Levine \& Blanchard 1977, 1980) when reintroduced to anemone hosts from which they had been isolated.

\section{NOTE ADDED IN PROOF}

Mercier \& Hamel (1994) found that, in Florida, a single specimen of the pycnogonid Pigrogromitus timsanus did not damage the sea anemone Bartholomea annulata, but multiple pycnogonids attached to a single anemone were harmful. As in our study, damage was evident only under laboratory conditions; Mercier \& Hamel (1994) were uncertain whether to classify this arthropod as a parasite of the actinian. 
Acknowledgements. This research was supported by National Science Council, Republic of China, grant NSC 84-2321-B019-002, and by a grant from the Ministry of Education, ROC, to J.-S.H. Research was conducted at the National Taiwan Ocean University, Keelung, Taiwan, ROC. We thank R. W. Buddemeier, A. Kuris, and N. Knowlton for helpful suggestions on the manuscript, A. J. Bruce for identifying the shrimp, and N. A. Slade for statistical advice.

\section{LITERATURE CITED}

Bruce AJ (1976) Coral reef Caridea and 'commensalism' Micronesica 12:83-98

Bruce AJ, Svoboda A (1983) Observations upon some pontoniine shrimps from Aqaba, Jordan. Zool Verh, Leiden 205: $1-44$

Carlgren O (1949) Synopsis of the Ptychodactiaria, Corallimorpharia and Actiniaria. K Sven Vetenskapsakad Handl (Ser 4) 1:1-121

Cheng TC (1991) Is parasitism symbiosis? A definition of terms and the evolution of concepts. In: Toft CA, Aeschlimann A, Bolis L (eds) Parasite-host associations: coexistence or conflict? Oxford Press, Oxford, p 15-36

Crawford JA (1992) Acclimation of the shrimp, Periclimenes anthophilus, to the giant sea anemone, Condylactis gigantea. Bull mar Sci 50:331-341

Dunn DF (1981) The clownfish sea anemones: Stichodactylidae (Coelenterata: Actiniaria) and other sea anemones symbiotic with pomacentrid fishes. Trans Am phil Soc 71 $1-115$

Fautin DG (1991) The anemonefish symbiosis: what is known and what is not. Symbiosis 10:23-46

Fautin DG, Allen GR (1992) Field guide to anemonefishes and their host sea anemones. Western Australian Museum, Perth

Godwin J, Fautin DG (1992) Defense of host actinians by anemonefishes. Copeia 1992:903-908

This article was presented by J. M. Shick (Senior Editorial Advisor), Orono, Maine, USA
Guo CC, Hwang JS, Fautin DG (in press) Host selection by shrimps symbiotic with sea anemones: a field survey and experimental laboratory analysis. J exp mar Biol Ecol

International Code of Zoological Nomenclature, 3rd edn (1985) International Trust for Zoological Nomenclature, London

Kuris AM (1974) Trophic interactions: similarity of parasitic castrators to parasitoids. Q Rev Biol 49:129-148

Levine DM, Blanchard OJ Jr (1977) Aspects of the symbiotic behavior of Penclimenes rathbunae Schmitt and Thor amboinensis (de Man) with their host tropical sea anemone, Stoichactis helianthus (Ellis), from Jamaica. Proc Indiana Acad Sci 86 (for 1976): 175

Levine DM, Blanchard OJ Jr (1980) Acclimation of two shrimps of the genus Periclimenes to sea anemones. Bull mar Sci $30: 460-466$

Mercier A, Hamel JF (1994) Deleterious effects of a pycnogonid on the sea anemone Bartholomed annulata. Can J Zool $72: 1362-1364$

Omori K, Yanagisawa Y, Hori N (1994) Life history of the caridean shrimp Periclimenes ornatus Bruce associated with a sea anemone in southwest Japan. J crust Biol 14: $132-145$

Smith WL (1977) Beneficial behavior of a symbiotic shrimp to its host anemone. Bull mar Sci 27:343-346

Sokal RR, Rohlf FJ (1969) Biometry: the principles and practice of statistics in biological research. Freeman, San Francisco

Steen RG (1988) The bioenergetics of symbiotic sea anemones (Anthozoa: Actiniaria). Symbiosis 5:103-142

Suzuki K, Hayashi KI (1977) Five caridean shrimps associated with sea anemones in central Japan. Publ Seto mar biol Lab 24:193-208

Thompson JN (1994) The coevolutionary process. University of Chicago, Chicago

Toft CA (1991.) An ecological perspective: the population and community consequences of parasitism. In: Toft CA, Aeschlimann A, Bolis L (eds) Parasite-host associations: coexistence or conflict? Oxford Press, Oxford, p 319-343

Manuscript first received: January 3,1995

Revised version accepted: May 8, 1995 